\title{
A Educação Ambiental como instrumento para a sustentabilidade
}

\section{The Environmental Education as a tool for sustainability}

\author{
Izadora Caroline Costa ${ }^{1}$, Régis Rogério Vicente Sartori ${ }^{2}$
}

Recebido: 21/06/2020. Aceito: 10/08/2020

\begin{abstract}
Resumo
O presente artigo tem como propósito analisar de modo crítico o conteúdo normativo da educação para a sustentabilidade no Brasil, em especial, o seu caráter interdisciplinar e, portanto, desautorizado de constituir uma disciplina formal autônoma. Na persecução de um desenvolvimento sustentável e, por consequência, de uma formação pedagógica com ele compatível, o nexo educação-ambiente internalizado pela legislação brasileira revela-se paradoxal, pois, tornado obrigatoriamente transverso, dificulta que seja cientificamente verticalizado e praticado.
\end{abstract}

Palavras-chave: Educação ambiental. Sustentabilidade. Desenvolvimento Sustentável. Direito Ambiental.

\begin{abstract}
The purpose of this article is to critically analyse the normative content of education for sustainability in Brazil, in particular, its interdisciplinary character and, therefore, disallowed from constituting an autonomous formal discipline. In the pursuit of sustainable development and, consequently, of pedagogical training compatible with it, the education-environment nexus internalized by Brazilian legislation proves to be paradoxical, since, made obligatorily transversal, it makes it difficult to be scientifically verticalized and practiced.
\end{abstract}

Keywords: Environmental Education. Sustainability. Sustainable Development. Environmental Law.

\section{Introdução}

Vivencia-se, na contemporaneidade, uma "incrivelmente humana crise ambiental" (SOUZA FILHO, 2015, p. 90), em que os limites da sustentabilidade planetária, em perigosa reiteração, prosseguem desafiados e até mesmo excedidos. Cogita-se que a interferência humana no ambiente é de tal monta a ponto de equiparar-se às forças geológicas na transformação do sistema terrestre, inaugurando uma nova época evolutiva, a do Antropoceno.

Nesse percurso, o conceito de desenvolvimento sustentável - em que pese as suas múltiplas aplicações, incluindo as meramente discursivas - se tornou a principal orientação para um presente e futuro capazes de compatibilizar o dinâmico equilíbrio ambiental e a necessidade de desenvolvimento humano, seja este compreendido de modo alargado, em semelhança às liberdades, ou restrito, sinônimo de crescimento econômico (SEN, 2010).

No entanto, para que o desenvolvimento sustentável se torne factível é necessário, em perspectiva basilar, de uma educação voltada para a sustentabilidade, capaz de abranger a amplitude do objeto ambiental,

1 Graduada em Direito e Pós-graduanda em Direito Constitucional pela Academia Brasileira de Direito Constitucional ABDCONST. E-mail: iccosta@mppr.mp.br

2 Graduado em Direito; Especialista em Direito do Estado pela Universidade Estadual de Londrina e Filosofia Política pela Unioeste; Mestrando em Governança e Sustentabilidade pelo ISAE. E-mail: rrvsartori@mppr.mp.br 
integrador de todas as formas de vida e dos elementos abióticos, como solo, água e ar.

Em âmbito internacional e doméstico, veda-se a prática da educação ambiental como disciplina formal curricular, em privilégio de seu caráter interdisciplinar. Ao mesmo tempo que essa prática difusa claramente se justifica, não necessariamente se concretiza, isto é, porque disseminada, falta um lugar para a educação ambiental, com fundamento na mesma racionalidade em que se afirma que "quando tudo é desenvolvimento sustentável, nada o é" (LEITE; CAETANO, 2012, p. 135).

Verifica-se, de todo modo, que uma das expressões da educação ambiental é a disciplina acadêmica de direito ambiental, lecionada no ensino superior predominantemente jurídico, mas também em cursos atinentes às ciências da vida e agrárias.

A partir dessas considerações, objetiva este estudo a análise do teor normativo da educação ambiental no Brasil e da incidência da disciplina de direito ambiental nas instituições de ensino superior nas capitais do sul do país. Para tanto, a partir do método dedutivo de abordagem, bem como do emprego de técnicas bibliográficas, documentais e estatísticas, pontua-se inicialmente os principais eventos informadores da educação ambiental e do direito ambiental em perspectiva internacional e nacional, demonstrando a correlação que estabelecem. Versa-se, na sequência, acerca do perfil institucionalizado da educação ambiental, da amplitude de seu conteúdo e da extensão de suas práticas, juntamente da problemática que tal enquadramento suscita. Aborda-se, por último, o viés pedagógico ambiental manifesto na disciplina de direito ambiental no contexto brasileiro, utilizando-se de dados regionais como ilustração.

\section{0 percurso internacional e doméstico de afirmação da educação ambiental}

A Organização das Nações Unidas (ONU) representa a principal força-motriz de evolução, sistematização e amadurecimento da interface educação-ambiente, tanto em seus aspectos de relativa autonomia temática quanto nos de evidente inter-relação. Nesse sentido, a legislação e as políticas públicas brasileiras referentes à educação ambiental e ao direito ambiental são influenciadas - quando não diretamente decorrentes - por marcos de política exterior, que passam a ser internalizados nos multiníveis domésticos de poder (DIAS, 2017, p. 16).

Historicamente, somente nas últimas décadas é que a questão ambiental foi incorporada à agenda pública global. Com efeito, são as décadas de 1960 e 1970 apontadas como o período de emergência da governança ambiental no mundo, sendo considerada como marco inaugural e institucional desse processo a Conferência das Nações Unidas sobre Meio Ambiente Humano, realizada em Estocolmo, na Suécia, em 1972 (VEIGA, 2013, p. 46).

Após décadas de ininterrupto crescimento econômico - a chamada "era de ouro" pós-Segunda Guerra -, a Conferência de Estocolmo ocorreu em um momento "marcado pelo forte questionamento tanto do modelo ocidental de desenvolvimento quanto do modelo socialista" (LAGO, 2006, p. 26), sobretudo pelas repercussões ambientais negativas advindas da industrialização, cujos efeitos transfronteiriços afetavam principalmen- 
te a população dos países ricos. Por sua vez, a preocupação dos países em desenvolvimento, como o Brasil, era proveniente da pobreza e da industrialização tardia, razão pela qual tornou-se emblemática a frase proferida em Estocolmo de que "a pobreza é a pior forma de poluição" (OLIVEIRA; MONT'ALVERNE, 2015, p. 122).

Naquele encontro, "o ponto de vista dos países menos desenvolvidos dominou as discussões em quase todos os assuntos e forçou [...] a ver os problemas ambientais em uma perspectiva global" (McCORMICK, 1992, p. 106). Como saldo da conferência, na Declaração de Estocolmo, representante do "nascimento do Direito Ambiental Internacional" (MAZZUOLI; TEIXEIRA, 2013, p. 200), afirma-se que "os países em desenvolvimento devem dirigir seus esforços para o desenvolvimento" ao mesmo tempo que os "países industrializados devem se esforçar para reduzir a distância que os separa dos países em desenvolvimento" (ORGANIZAÇÃO DAS NAÇÕES UNIDAS, 1972). Além disso, o documento determinou as "prioridades das futuras negociações sobre meio ambiente" (LAGO, 2006, p. 48), entre elas, a de especial ênfase à educação ambiental com vistas ao enfrentamento dos problemas existentes.

Em 1975, como reflexo da Conferência de Estocolmo, a Organização das Nações Unidas para a Educação, a Ciência e a Cultura (UNESCO) promoveu em Belgrado, na Iugoslávia, o I Seminário Internacional de Educação Ambiental, do qual resultou a Carta de Belgrado, documento fundante de uma "quadratura epistemológica da educação ambiental" (DIAS, 2017, p. 33). De acordo com o texto, a educação ambiental constitui um processo amplo, contínuo e interdisciplinar, formal ou não, que abrange dimensões econômicas, culturais e sociopolíticas, apto à superação de problemas sociais e econômicos articulados com a temática ambiental, capacitado a integrar diferenças regionais e interesses nacionais (McCORMICK, 1992, p. 121). Com base nesse entendimento, ainda em 1975, a UNESCO criou o Programa Internacional de Educação Ambiental, em andamento até os dias atuais, cujo propósito é estimular e divulgar experiências mundiais de educação ambiental, além de estabelecer uma base de dados de ações e instituições voltadas para esse fim (DIAS, 2017, p. 38).

Nesse lastro, a UNESCO realizou em 1977 a I Conferência Intergovernamental sobre Educação Ambiental, realizada em Tbilisi, na Geórgia (país da Ásia central), evento considerado referência no tema. No encontro, foram aprofundadas as questões constituintes da Carta Belgrado com o intuito de fomentar uma “estrutura global para a educação ambiental” (DIAS, 2017, p. 43-44).

Em 1981, no Brasil, instituiu-se a Política Nacional do Meio Ambiente (Lei n. 6.938), ainda hoje compreendida como integrante da "vanguarda legislativa do Direito Ambiental brasileiro" (SARLET; FENSTERSEIFER, 2014, p. 280), que, em diálogo com a Declaração de Estocolmo e a Carta de Belgrado, reconhece o caráter uno e indivisível do ambiente, entendido como "o conjunto de condições, leis, influências e interações de ordem física, química e biológica, que permite, abriga e rege a vida em todas as suas formas”, e, ainda, a relevância da "educação ambiental a todos os níveis de ensino", de modo estimular a participação social ativa na defesa ambiental (BRASIL, 1981).

Em âmbito internacional, a divulgação do relatório Nosso Futuro Comum, em 1987, inovou ao trazer a terminologia "desenvolvimento sustentável", analisado como, "em tese, a mais generosa visão do futuro" (VEIGA, 2015, p. 23). De acordo com o documento: 


\begin{abstract}
A humanidade é capaz de tornar o desenvolvimento sustentável - de garantir que ele atenda às necessidades do presente sem comprometer a capacidade de as gerações futuras atenderem também as suas. $\mathrm{O}$ conceito de desenvolvimento sustentável tem, é claro, limites - não limites absolutos, mas limitações impostas pelo estágio atual da tecnologia e da organização social, no tocante aos recursos ambientais, e pela capacidade da biosfera de absorver os efeitos da atividade humana. Mas tanto a tecnologia quanto a organização social podem ser geridas e aprimoradas a fim de proporcionar uma nova era de crescimento econômico (COMISSÃO MUNDIAL SOBRE MEIO AMBIENTE E DESENVOLVIMENTO, 1991, p. 9).
\end{abstract}

O conceito de desenvolvimento sustentável afirmou-se como um "fenômeno ao mesmo tempo multissetorial e multiterritorial" (VEIGA, 2015, p. 22), centrado na "novíssima ideia de que as futuras gerações merecem tanta atenção quanto as atuais" (LUCON, 2013, p. 31), de modo a atribuir responsabilidade intra e intergeracionais com o ambiente e todas as formas de vida. A partir da noção de que se baseia em, pelo menos, três pilares - o econômico, o social e o ambiental -, o desenvolvimento sustentável "a partir de então, [...] recebeu grande aceitação por quase a totalidade de correntes políticas, éticas, econômicas e científicas” (OLIVEIRA; MONT'ALVERNE, 2015, p. 128).

Internalizando o conceito de desenvolvimento sustentável, a Constituição da República (CR) de 1988, em termos formais, representa um marco para o direito ambiental e a educação ambiental brasileiros. Com ela, inaugurou-se um capítulo específico sobre o direito ao ambiente, qualificado como ecologicamente equilibrado, bem como foi recepcionada a Política Nacional de Meio Ambiente (Lei n. 6.938/1981), isto é, legitimou-se a continuidade pós 1988 de seus efeitos. Ao mesmo tempo, assegurou-se à educação ambiental uma nova topologia jurídica, com status constitucional (DIAS, 2017, p. 61). Conforme a CR, incumbe ao Poder Público "promover a educação ambiental em todos os níveis de ensino e a conscientização pública para a preservação do meio ambiente" (BRASIL, 1988).

Vinte anos após a Conferência de Estocolmo, aconteceu a Conferência das Nações Unidas sobre Meio Ambiente e Desenvolvimento, realizada na cidade do Rio de Janeiro, em junho de 1992. Credita-se a escolha do Brasil como anfitrião da Rio-92, como também foi referenciada, a fatores como a promulgação "de uma verdadeira Constituição Ambiental" (SARLET; FENSTERSEIFER, 2014, p. 32, grifo do autor) e também ao "exame preocupado" do contexto ambiental brasileiro contido no relatório Nosso Futuro Comum (VEIGA, 2013, p. 89).

Na Rio-92, sob o mote do desenvolvimento sustentável, foi produzida a Declaração do Rio de Janeiro, na qual foram arrolados os "grandes princípios normativos do Direito Internacional do Meio Ambiente" (OLIVEIRA; MONT'ALVERNE, 2015, p. 123); a Agenda 21, "um plano de ação e instrumento-diretriz do desenvolvimento sustentável" (LUCON, 2013, p. 31); a Declaração de Princípios sobre a Floresta; e dois tratados, a Convenção sobre Diversidade Biológica e a Convenção-Quadro das Nações Unidas sobre Mudança do Clima. Gerou-se, ainda, o Tratado de Educação Ambiental para Sociedades Sustentáveis e Responsabilidade Global, que, em que pese ser mencionado como tratado, não origina repercussões legais. Todos os documentos confeccionados na Rio-92 fazem menção, detidamente ou de passagem, à educação ambiental.

Internacionalmente, a Declaração do Rio de Janeiro estabeleceu o status jurídico do conceito de de- 
senvolvimento sustentável trazido pelo relatório Nosso Futuro Comum. Do mesmo modo, "a partir das convenções [da biodiversidade e climática], a construção de um conceito mais abrangente de desenvolvimento sustentável ganhou consistência jurídica e tornou-se parte do Direito positivo" (RIBEIRO, 2005, p. 119).

O Tratado de Educação Ambiental para Sociedades Sustentáveis e Responsabilidade Global, em tom assemelhado aos documentos produzidos desde a Carta de Belgrado, expressa o feitio crítico e emancipatório da educação ambiental na busca do que se propugna como sociedades sustentáveis, entendidas como aquelas cuja educação esteja voltada a forjar cidadãos, em amplo sentido (DIAS, 2017, p. 79).

Em termos legais, o Brasil estabeleceu a sua Política Nacional de Educação Ambiental (Lei n. 9.795) em 1999, fixando as estruturas regulatórias básicas da educação ambiental, vinculando os processos formais de educação a práticas sociais instrutivas e, sob influência do percurso cumprido e aprofundado desde Estocolmo, dispõe que "a educação ambiental não deve ser implantada como disciplina específica no currículo de ensino" (BRASIL, 1999).

No ano 2000, a ONU promoveu em sua sede a Cúpula do Milênio, ocasião em que 189 países, incluindo o Brasil, comprometeram-se com os Objetivos de Desenvolvimento do Milênio (ODM), conjunto de metas a serem alcançadas até 2015, entre elas, a de garantir qualidade de vida e respeito ao meio ambiente. Cumprida essa etapa, os ODM foram substituídos e ampliados pelos Objetivos de Desenvolvimento Sustentável (ODS), conjunto de 17 objetivos e 169 metas componentes da Agenda 2030, vigente a partir de 2016. Os ODS têm como base os "cinco Ps", alusivos às categorias pessoas, planeta, prosperidade, paz e parceria, que, de maneira sistêmica e sinérgica, intentam a "ampliação da cidadania, da liberdade, da autonomia e da intervenção direta dos cidadãos na busca de alternativas que permitam uma vivência e convivência dignas, voltadas para o bem comum" (DIAS, 2017, p. 105). Entre os ODS, está o de assegurar a educação inclusiva e equitativa e de qualidade, e promover oportunidades de aprendizagem ao longo da vida para todos.

Por seu turno, em 2002, a ONU estabeleceu a Década da Educação para o Desenvolvimento Sustentável, cuja vigência se deu entre 2005 e 2014. Segundo a UNESCO, o principal objetivo da proposta foi integrar princípios, valores e práticas de desenvolvimento sustentável em todos os aspectos da educação e do ensino, de modo que esse esforço encorajasse "mudanças de comportamento para criar um futuro mais sustentável em termos de integridade do meio ambiente, da viabilidade econômica, e de uma sociedade mais justa para as atuais e futuras gerações” (UNESCO, 2005, p. 57). Em relatório de avaliação da Década da Educação para o Desenvolvimento Sustentável, apesar dos avanços, consignou-se a urgência de mais inovação e monitoramento para ampliar e comprovar a eficácia de boas práticas pedagógicas. Por essa razão, criou-se o Programa de Ação Global sobre Educação para o Desenvolvimento Sustentável, de modo a contribuir substancialmente para a continuidade da agenda pós 2014. As partes interessadas, sejam países ou empresas, podem contribuir para a implementação do Programa por intermédio de variados projetos desenvolvidos global, regional e/ou localmente, cuja gestão é de responsabilidade da UNESCO.

Por fim, o mais recente grande encontro sobre a questão ambiental foi a Conferência das Nações Unidas sobre Desenvolvimento Sustentável, realizada na cidade do Rio de Janeiro, em 2012. Ficou conhecida por 
Rio +20 por ocorrer vinte anos depois da Rio-92 e, ainda, definir a agenda do desenvolvimento sustentável para as próximas décadas. Ao seu término, aproximadamente 300 instituições de ensino superior assinaram o relatório O Futuro que Queremos, com o compromisso de inserção da temática do desenvolvimento sustentável em seus currículos. De acordo com o documento, “o processo educativo deve ser orientado para a resolução de problemas concretos do meio ambiente, mediante enfoques interdisciplinares e de participação ativa e responsável de cada indivíduo e da coletividade" (DIAS, 2017, p. 114).

Em apanhado, tem-se hoje, com amparo da CR e das Leis n. 6.938/1981 e 9.795/1999, uma Política Nacional de Educação Ambiental, a qual envolve em sua esfera de ação, além dos órgãos e entidades integrantes do Sistema Nacional de Meio Ambiente (SISNAMA), instituições educacionais públicas e privadas, órgãos públicos da União, dos Estados, do Distrito Federal e dos Municípios, e organizações não-governamentais com atuação em educação ambiental.

Importa frisar que a Lei n. 9.795/1999 promoveu a separação entre a educação formal e não formal. Quanto à educação ambiental não formal, estabeleceu que envolve as ações e práticas educativas voltadas à sensibilização da coletividade sobre as questões ambientais e à sua organização e participação na defesa da qualidade do ambiente, ou seja, determina que a sociedade deve ser formada para questões ambientais. Segundo a normativa, o Poder Público deve, por exemplo, educar a população realizando a difusão, por intermédio dos meios de comunicação de massa, em espaços nobres, de programas e campanhas educativas, e de informações acerca de temas relacionados ao ambiente.

De outro lado - e em consonância com o interesse precípuo desta pesquisa -, a Lei n. 9.795/1999 informa que a educação ambiental deve abranger também a educação formal, no âmbito dos currículos das instituições de ensino públicas e privadas, englobando a educação básica, educação infantil, ensino fundamental, ensino médio, educação superior, educação especial, educação profissional e, ainda, a educação de jovens e adultos, isto é, integrando todas as categorias pedagógicas nacionalmente institucionalizadas.

\section{A educação ambiental como problema prático}

A proteção ao meio ambiente é prevista na Constituição da República Federativa do Brasil de 1988 como um direito fundamental, na qual a consagração de um meio ambiente ecologicamente equilibrado e os valores ecológicos são colocados no "coração" do sistema jurídico pátrio, constituindo-se um verdadeiro Estado Democrático, Social e Ecológico de Direito (SARLET; FENSTERSEIFER, 2019, p. 45).

Em virtude da constitucionalização da tutela ecológica "a proteção ambiental passou a ser tratada como uma política pública de expressão nacional”, vinculando tanto o Poder Público quanto a sociedade em geral (SARLET; FENSTERSEIFER, 2019, p. 48-49), conforme se verifica na redação do artigo 225 da Constituição que prevê que "todos têm direito ao meio ambiente ecologicamente equilibrado, bem de uso comum do povo e essencial à sadia qualidade de vida, impondo-se ao Poder Público e à coletividade o dever de defendê-lo e preservá-lo para as presentes e futuras gerações". 
Para a efetivação dos postulados nacionais e internacionais de proteção ambiental é indispensável uma cooperação entre os diversos atores sociais para o enfrentamento da atual crise ambiental que se instaurou ao longo dos anos em todo o mundo, especialmente quanto à degradação ambiental. Assim, para que haja a possibilidade de reversão de suas causas, é necessária uma educação ambiental pautada na mudança “dos sistemas de conhecimento, dos valores e dos comportamentos gerados pela dinâmica de racionalidade existente, fundada no aspecto econômico do desenvolvimento" (JACOBI, 2003, p. 190).

Historicamente, a proteção ambiental foi fruto de diversas lutas sociais e políticas, na qual os movimentos ambientalistas foram determinantes para a consolidação da tutela ecológica no país (SARLET; FENSTERSEIFER, 2019, p. 47). Nesta conjuntura, a educação ambiental foi idealizada inicialmente como parte da pauta dos movimentos ambientalistas, cujo objetivo era a conscientização dos indivíduos acerca do acesso e má distribuição dos recursos naturais. Em um segundo momento, a educação ambiental se tornou mais abrangente, passando a ter um cunho essencialmente educativo, voltado ao campo educacional a partir do estudo de suas tradições, teorias e saberes, para dar uma resposta à crise ambiental existente (MATOS, 2009, p. 25).

Neste contexto, a educação ambiental assumiu um papel transformador para motivar e sensibilizar as pessoas para a mudanças sociopolíticas em prol da qualidade de vida, constituindo-se, de acordo com Jacobi (2003, p. 193), como uma "ferramenta de mediação entre culturas, comportamentos e interesses de grupos sociais para a construção das transformações desejadas". Ademais, o autor entende que a educação ambiental:

Assume cada vez mais uma função transformadora, na qual a corresponsabilização dos indivíduos torna-se um objetivo essencial para promover um novo tipo de desenvolvimento - o desenvolvimento sustentável. Entende-se, portanto, que a educação ambiental é condição necessária para modificar um quadro de crescente degradação socioambiental (p. 193).

Essa matriz contemporânea de educação ambiental é tida como um elemento de transformação social, orientada pelo fortalecimento dos sujeitos e pela reestruturação das relações econômicas por meio da articulação de espaços formais ${ }^{3}$ e não formais de educação (LOUREIRO, 2004 p. 67-72).

De Estocolmo e Belgrado até os dias atuais, ocorreram múltiplos eventos informadores da educação ambiental, muitos deles com abrangência e repercussões mais restritas, com alcance regional e local. Com base nos grandes eventos internacionais listados neste estudo, representantes do "estado da arte" das temáticas ambientais em seus momentos históricos de ocorrência, é possível verificar que configuram a narrativa de um "projeto cujo potencial empírico se protrai" (DIAS, 2017, p. 142), no qual a principiologia pedagógica e jus ambiental é discursivamente ratificada e são reiterados os apelos à mudança de comportamento social em relação ao ambiente. Ainda, é permeada por constantes questionamentos sobre os rumos existenciais da humanidade e sobre o nexo que torna sub-aplicados os projetos educacionais e político-jurídicos na área ambiental,

3 No âmbito do ensino infantil, fundamental e especial, à título de exemplificação, merece destaque o programa Agrinho, que leva às escolas da rede pública de ensino informações sobre saúde e segurança pessoal e ambiental, a partir de uma proposta pedagógica baseada na inter e transdisciplinaridade da temática. Esse programa de educação ambiental é um dos maiores programas de responsabilidade social, idealizado pelo Sistema FAEP e resultado da parceria entre o SENAR-PR, FAEP, o governo do Estado do Paraná, mediante as Secretarias de Estado da Educação, da Justiça e da Cidadania, do Meio Ambiente e Recursos Hídricos, da Agricultura e do Abastecimento (AGRINHO, 2020). 
em que pese o manancial técnico disponível em eventos, relatórios e documentos oficiais.

No limite, esse arcabouço epistêmico e metodológico não tem contribuído de maneira consistentemente significativa para alterar os níveis de degradação ambiental, ou seja, prossegue um hiato na relação teoria-prática (BERTOLINI; CAÚLA, 2013, p. 45), quando, em verdade, “os processos do conhecer e do agir reivindicam vinculação objetiva” (DIAS, 2017, p. 29). Neste sentido, Matos (2009) pontua que:

\begin{abstract}
Esse distanciamento entre o que é recomendado pelas determinações e publicações e o que acontece nas práticas sociais (na maior parte) pode ser explicado por diferentes fatores. É possível explicar este distanciamento considerando, primeiramente, as dualidades que caracterizam a sociedade moderna. Se atualmente ainda vivemos em uma sociedade com uma concepção dualista que fragmenta o mundo e o conhecimento, e a educação ambiental surgiu nesta sociedade, este campo acaba também sendo caracterizado por dualismos que separam, por exemplo a teoria e a prática (p. 105).
\end{abstract}

O distanciamento entre a teoria e a prática também pode estar relacionado à recente implantação da educação ambiental na academia, que estruturou o campo teórico e conceitual a pouco tempo no país (MATOS, 2009, p. 105).

Não obstante, outra razão explicativa desse contexto diz respeito ao conteúdo subjacente à educação ambiental, formal e informal. Trata-se, a priori, de uma "educação política" (GOHN, 2011, p. 60), constituinte de uma "prática social humanizante do humano" (QUINTAS, 2009, p. 36), isto é, articuladora de esferas e dimensões civilizatórias essenciais. Atravessa a esfera privada do indivíduo, em sua capacidade de tomar decisões livres e na interdependência da sociedade civil em relação ao Estado; a esfera coletiva, de organização social e popular; e também a esfera democrática, em sua vocação para o protagonismo de sujeitos e organizações (GOHN, 2011, p. 62-63). Além disso, impulsiona-se de forma crítica, transformadora e emancipadora, pois traz a lume contradições sociais, interage com um devir solidário e pressupõe a autodeterminação pessoal e comunitária, configuração que desafia interesses do status quo (QUINTAS, 2009, p. 41).

Outra razão a ser levada em conta é a da amplitude de seu propósito, especialmente porque produto da ciência contemporânea, herdeira do Iluminismo, fragmentada e especializada em essência. Em contraponto, a prática educativa formal ambiental proposta pelos documentos internacionais e nacionais, "ampla, difusa, corresponsável” (QUINTAS, 2009, p. 55), busca estabelecer conexões entre os campos do conhecimento humano e superar a visão uno-científica. Em outros termos,

\footnotetext{
A educação ambiental aponta para a sua contribuição na qualidade de ato pedagógico, práxis social e dada a sua complexidade, na construção de sociedades sustentáveis, as quais requerem que sejam ecológica e ambientalmente prudentes, economicamente viáveis, socialmente justas, culturalmente diversas, territorialmente suficientes e politicamente participativas e democráticas (PUHL, 2016, p. 89).
}

Há, nesse sentido, um comando paradoxal no cerne da educação formal para a sustentabilidade: ao mesmo tempo em que deve "irradiar efeitos", só alcança materialidade mediante o diálogo com as disciplinas acadêmicas formais, "estruturas científicas altamente compatibilizadas e autorreferentes", o que resulta no arrefecimento de sua "índole multidisciplinar” (QUINTAS, 2009, p. 70-72). 
Por último, há o aspecto do enforcement legislativo no contexto brasileiro e mundial. Os documentos internacionais, particularmente os relativos à educação ambiental, encerram disposições puramente políticas ou as chamadas normas de soft law, legítimos "guias de conduta sem obrigação" (GONÇALVES; COSTA, 2015, p. 104), de cumprimento facultativo. No Estado brasileiro, "o cumprimento dos preceitos legais pertinentes à educação ambiental revela-se de modo tímido e incompatível com a premissa de mudança de comportamento e de conscientização ambiental" (BERTOLINI; CAÚLA, 2013, p. 47). A complexificar esse contexto, perdura outra questão de ordem cultural, a de que "os atores sociais ainda vivem na utopia de que direitos e deveres só têm aplicabilidade mediante a fiscalização" (BERTOLINI; CAÚLA, 2013, p. 57).

A expansão da educação ambiental no Brasil demanda, portanto, condições internas favoráveis, por meio da mobilização e do diálogo entre os diversos setores e fragmentos sociais em torno da educação ambiental, especialmente por meio da atuação estatal e de entes privados (Matos, 2009, p. 100). Essa atuação conjunta no ambiente educativo potencializa a difusão de conhecimento, a capacitação dos profissionais e da comunidade universitária, bem como contempla as inter-relações do meio natural com o social para a promoção de um desenvolvimento verdadeiramente sustentável (JACOB, 2003, p. 189).

\section{Limites e possibilidades da educação ambiental: análise a partir da disciplina de direito ambiental como expressão pedagógica para a sustentabilidade}

Embora, como aludido, existam dificuldades de ordem prática na concretização da educação formal ambiental como legalmente dimensionada, é possível identificar no direito ambiental - enquanto disciplina do ensino superior - uma de suas expressões. Em outros termos, metodologicamente, permite-se tratar a educação ambiental como gênero do qual o direito ambiental é uma das espécies. Tem-se, nessa racionalidade, que a carga de sentido constituinte da pedagogia para a sustentabilidade se manifesta nos institutos e procedimentos jusambientais.

Nesse sentido, é de importante valia a análise das mais recentes Diretrizes Curriculares Nacionais do curso de graduação em Direito, de 2004 e 2018, sendo esta substituta daquela, editadas pelo Conselho Nacional de Educação, com especial atenção ao enfoque da educação ambiental e do direito ambiental.

De acordo com o artigo $5^{\circ}$ da Resolução n. 9 de 2004, o curso de graduação em Direito deveria contemplar, em seu projeto pedagógico e em sua organização curricular, conteúdos e atividades que atendam aos seguintes eixos interligados de formação:

I - Eixo de Formação Fundamental, tem por objetivo integrar o estudante no campo, estabelecendo as relações do Direito com outras áreas do saber, abrangendo dentre outros, estudos que envolvam conteúdos essenciais sobre Antropologia, Ciência Política, Economia, Ética, Filosofia, História, Psicologia e Sociologia. II - Eixo de Formação Profissional, abrangendo, além do enfoque dogmático, o conhecimento e a aplicação, observadas as peculiaridades dos diversos ramos do Direito, de qualquer natureza, estudados sistematicamente e contextualizados segundo a evolução da Ciência do Direito e sua aplicação às mudanças sociais, econômicas, políticas e culturais do Brasil e suas relações internacionais, incluindo-se necessariamente, dentre outros condizentes com o projeto pedagógico, conteúdos essenciais sobre Direito Constitucional, Direito Administrativo, Direito Tributário, Direito Penal, Di- 
reito Civil, Direito Empresarial, Direito do Trabalho, Direito Internacional e Direito Processual (sem grifos no original).

Como se verifica, na Resolução n. 9, de 2004, inexiste menção à educação ambiental, em explícita contrariedade ao ordenamento jurídico nacionalmente estabelecido e, por consequência, aos ditames internacionalmente acordados sobre o tema. Assume-se, desse modo, que todos os cursos de graduação em Direito no Brasil estiveram expressamente autorizados a não incluir a transversalidade da educação ambiental no rol de suas disciplinas, cuja duração perfaz cinco anos. Em igual medida, em pese as tratativas e legislações que alçaram o direito ambiental como disciplina formal autônoma, também este é olvidado na referida resolução, deixando a cargo da discricionariedade de cada instituição de ensino superior implementá-lo ou não. Um quadro que, em perspectiva institucional, perdurou por quase quinze anos.

Por sua vez, a vigente Resolução n. 5, de 2018, menciona a previsão de:

[...] tratamento transversal dos conteúdos exigidos em diretrizes nacionais específicas, tais como as políticas de educação ambiental [...]". Junto a isso, informa que as instituições de ensino superior "poderão [...] definir ênfases em determinado(s) campo(s) do Direito e articular novas competências e saberes necessários aos novos desafios que se apresentem ao mundo do Direito, tais como: Direito Ambiental [...]" (sem grifos no original).

Além de evidenciar a tardia e anacrônica inserção da educação ambiental no currículo jurídico, a Resolução n. 5 mantém a determinação da resolução revogada acerca da disciplina de direito ambiental, isto é, a reafirma como facultativa e, tão preocupante quanto, a ela se refere como ilustração dos "novos desafios" apresentados à seara jurídica, evidenciando absoluto descompasso com a emergência e fortalecimento do direito ambiental, cuja origem remonta à década de 1970 do século passado, e com a crise ambiental desde lá sistematicamente aprofundada.

De toda sorte, em consonância com o mote do desenvolvimento sustentável, as instituições de ensino superior entenderam que o estudo formal e legal da sustentabilidade deve ser tratado de forma específica nos cursos de Direito, dado, entre variadas repercussões, o vínculo que estabelece com a sociedade civil e o mercado.

No intento de ilustrar essa assertiva, pesquisou-se a respeito da existência ou não da disciplina de direito ambiental, em 2019, nas matrizes curriculares de instituições de ensino superior das capitais do sul do Brasil. A busca pela disciplina se deu pelo nome "tradicional", correntemente aceito - direito ambiental -, e por terminologias correlatas. Como exemplifica Milaré (2018, p. 253), o direito ambiental pode ser referido como "direito ecológico, direito de proteção da natureza, direito do meio ambiente, direito do ambiente", entre outros.

Analisou-se a menção ao direito ambiental nas grades curriculares dos cursos de direito existentes nas capitais da Região Sul do país, por meio da amostra de 20 cursos de Direito presentes no município de Curitiba (Quadro 1), dos 4 existentes em Florianópolis (Quadro 2) e, por fim, dos 15 cursos em Porto Alegre (Quadro 3), conforme dados do Ministério da Educação (2020). São as informações, expressas em listagem e gráficos: 
Quadro 1 - Disciplina de direito ambiental em faculdades de direito em Curitiba

CURITIBA/PR

\begin{tabular}{|c|c|c|}
\hline INSTITUIÇÃO & PERÍODO & CARGA HORÁRIA \\
\hline PONTIFÍCIA UNIVERSIDADE CATÓLICA DO PARANÁ - PUCPR & $9^{\circ}$ & 60 \\
\hline $\begin{array}{l}\text { FACULDADE DE INOVAÇÃO TECNOLÓGICA DE CURITIBA } \\
\text { FACCESUMAR }\end{array}$ & $10^{\circ}$ & - \\
\hline FACULDADE DE TECNOLOGIA INSPIRAR & $8^{\circ}$ & 40 \\
\hline FACULDADE DE EDUCAÇÃO SUPERIOR DO PARANÁ - FESP/PR & $10^{\circ}$ & 60 \\
\hline UNIVERSIDADE TUITI DO PARANÁ - UTP & $8^{\circ}$ & 40 \\
\hline UNIVERSIDADE FEDERAL DO PARANÁ - UFPR & $5^{\circ}$ & 60 \\
\hline FAE - CENTRO UNIVERSITÁRIO & $10^{\circ}$ & 72 \\
\hline CENTRO UNIVERSITÁRIO CAMPOS DE ANDRADE - UNIANDRADE & - & - \\
\hline CENTRO UNIVERSITÁRIO CURITIBA - UNICURITIBA & $10^{\circ}$ & 36 \\
\hline CENTRO UNIVERSITÁRIO UNIDOMBOSCO & $10^{\circ}$ & 40 \\
\hline CENTRO UNIVERSITÁRIO INTERNACIONAL - UNINTER & $10^{\circ}$ & 40 \\
\hline CENTRO UNIVERSITÁRIO AUTÔNOMO DO BRASIL - UNIBRASIL & $6^{\circ}$ & - \\
\hline FACULDADE CURITIBANA - FAC & - & - \\
\hline FACULDADE PARANAENSE - FAPAR & & 30 \\
\hline FACULDADE ESTÁCIO DE CURITIBA & $8^{\circ}$ & - \\
\hline FACULDADES INTEGRADAS SANTA CRUZ DE CURITIBA & $9^{\circ}$ & 72 \\
\hline CENTRO UNIVERSITÁRIO OPET & $8^{\circ}$ & 36 \\
\hline
\end{tabular}

Não possui: Universidade Positivo - UP

Fonte: Os autores, 2020.

Quadro 2 - Disciplina de direito ambiental em faculdades de direito em Florianópolis

FLORIANÓPOLIS/SC

\begin{tabular}{|c|c|c|}
\hline INSTITUIÇÃO & PERÍODO & CARGA HORÁRIA \\
\hline FACULDADE CESUSC & $8^{\circ}$ & 40 \\
\hline UNIVERSIDADE DO SUL DE SANTA CATARINA - UNISUL & $6^{\circ}$ & 30 \\
\hline FACULDADE DE EDUCAÇÃO DE SANTA CATARINA - FAESC & - & 30 \\
\hline FACULDADE ESTÁCIO DE FLORIANÓPOLIS & $8^{\circ}$ & - \\
\hline
\end{tabular}

Fonte: Os autores, 2020. 
Quadro 3 - Disciplina de direito ambiental em faculdades de direito em Porto Alegre

PORTO ALEGRE/RS

\begin{tabular}{|c|c|c|}
\hline INSTITUIÇÃO & PERÍODO & CARGA HORÁRIA \\
\hline CENTRO UNIVERSITÁRIO RITTER DOS REIS UNIRITTER & $10^{\circ}$ & - \\
\hline $\begin{array}{l}\text { PONTIFÍCIA UNIVERSIDADE CATÓLICA DO RIO GRANDE DO SUL - } \\
\text { PUCRS }\end{array}$ & $9^{\circ}$ & 30 \\
\hline CENTRO UNIVERSITÁRIO METODISTA - IPA & OPTATIVA & 40 \\
\hline FACULDADE DOM BOSCO DE PORTO ALEGRE - FDB & OPTATIVA & 68 \\
\hline $\begin{array}{l}\text { FACULDADE ESTÁCIO DO RIO GRANDE DO SUL - ESTÁCIO } \\
\text { FARGS }\end{array}$ & $8^{\circ}$ & - \\
\hline FACULDADES INTEGRADAS SÃO JUDAS TADEU & $10^{\circ}$ & - \\
\hline FACULDADES JOÃO PAULO II - CAMPUS PORTO ALEGRE - FJP & $6^{\circ}$ & 72 \\
\hline CENTRO UNIVERSITÁRIO - FADERGS & - & - \\
\hline FACULDADE SÃO FRANCISCO DE ASSIS - UNIFIN & OPTATIVA & - \\
\hline FACULDADE MONTEIRO LOBATO - FATO & $2^{\circ}$ & 72 \\
\hline FACULDADE MERIDIONAL & $10^{\circ}$ & 80 \\
\hline $\begin{array}{l}\text { FACULDADE DE DIREITO DA FUNDAÇÃO ESCOLA SUPERIOR DO } \\
\text { MINISTÉRIO PUUBLICO }\end{array}$ & $9^{\circ}$ & 72 \\
\hline FACULDADE PORTO-ALEGRENSE - FAPA & OPTATIVA & - \\
\hline
\end{tabular}

NÃO POSSUI: FACULDADE IBGEN; UNIVERSIDADE DO VALE DO RIO DOS SINOS - UNISINOS

Fonte: Os autores, 2020.

Verifica-se que das instituições de ensino de Curitiba, 94,4\% possuem o curso de direito ambiental na grade curricular e apenas 5,6\% não possuem. Em Florianópolis, 100\% das universidades possuem a disciplina em seus currículos. Por seu turno, em Porto Alegre, 86,7\% das instituições de ensino superior possuem, sendo que somente $13,3 \%$ não integram o curso em sua grade. Ademais, naquelas que possuem a disciplina, 4 inseriram-na como optativa. Do saldo dessa amostra pontual, nota-se que a maioria das instituições de ensino das capitais do sul do país tratam da disciplina de direito ambiental, mesmo que a vigente resolução do Conselho Nacional de Educação a informe como opcional.

Assim como os egressos de outros cursos, os das escolas de Direito exercem atividades que afetam, direta e indiretamente, relevantes aspectos da vida em comunidade. Em particular, muitos operadores jurídicos que passaram por estas instituições de ensino superior exercem atividades ligadas aos poderes de Estado, seja na elaboração de leis, em atos da administração pública ou como juízes e membros do Ministério Público. Dessa forma, é essencial que se oferte um patamar razoável de conhecimento acerca das questões ambientais nos currículos jurídicos. Nesse ensejo:

O saber ambiental ocupa seu lugar no vazio deixado pelo progresso da racionalidade científica, como sintoma de sua falta de conhecimento e como sinal de um processo interminável de produção teórica e de ações práticas orientadas por uma utopia: a construção de um mundo sustentável, democrático, igualitário e diverso (LEFF, 2001, p. 17).

Infere-se, com base nesse elenco de informações, que, mesmo sem ser legalmente exigido nos currícu- 
los, o direito ambiental encontra-se largamente implementado nas instituições de ensino superior. Suscita-se, em correspondência, que a educação ambiental como disciplina acadêmica formal - integrante de todos os níveis de ensino, incluindo o superior - poderia resultar em condições mais favoráveis para a sustentabilidade social, econômica e ambiental. Não se questiona, portanto, a composição interdisciplinar da educação ambiental, mas, sim, o impedimento de que também possa ser oferecida de maneira autônoma, reforçando seu sentido e destinação.

Com base nas tabelas trazidas, percebe-se que a implementação do direito ambiental, em vez de derivar de imposição normativa, decorre da constatação empírica de sua necessidade, da exigência de uma demanda prática de atuação continuada. Em outros termos, o direito ambiental é reconhecido como relevante no balizamento dos direitos em litígio e em seu aspecto preventivo, antecedente ao dano.

Por sua vez, se a extensão difusa das práticas educacionais ambientais dificulta sua efetividade pedagógica, a existência de uma disciplina de educação ambiental proporcionaria um lócus institucional para que se desenvolvesse, sem prejuízo de sua interdisciplinaridade. Assim estabelecida, na aliança entre autonomia e diálogo prático com outras disciplinas, a educação ambiental seria revestida de novo significado, de notória identificação e, consequentemente, de viés mais efetivo, preenchendo de maior materialidade o dever ser da norma. Estaria inserida, enfim, na lógica especializada deste recorte histórico, embora prosseguisse vocacionada à inter-relação disciplinar.

\section{Considerações finais}

Como valor, a educação ambiental é fartamente legitimada por eventos internacionais e legislações domésticas, como no caso brasileiro. Esse lastro normativo e científico, apesar de politicamente significativo, não reflete necessariamente a adoção prática das medidas nele defendidas. Dada a amplitude de seu objeto - o ambiente -, a educação ambiental, para além do reconhecimento de seu caráter informal, desde logo foi entendida como ação interdisciplinar formal em todos níveis de ensino.

No entanto, como se verifica reiteradamente em eventos e documentos sobre o tema, ao se propor tão abrangente, tornou-se de desafiante concretização e aderência fática, comprometendo o seu sentido de ser. A educação ambiental passou a adquirir um caráter simbólico, entre outros fatores, pelo exercício pedagógico vigorosamente especializado da contemporaneidade.

De seu lado, o direito ambiental - enquanto disciplina formal do ensino superior e uma das manifestações da educação ambiental -, embora de oferta facultativa nos currículos universitários, é frequentemente disponibilizado, como se verificou na análise das disciplinas oferecidas pelas instituições de ensino superior.

Considerou-se, portanto, que a pertinência da educação ambiental como disciplina formal, aliada a manutenção de sua interdisciplinaridade, reforça a finalidade de gestão pedagógica e protetiva do bem ambiental, contribuindo, inclusive, para a sua efetivação transversa. De outro modo, a educação ambiental como instrumento para a sustentabilidade prosseguirá como urgente promessa, angariando efeitos incertos. 


\section{Referências}

SISTEMA FAEP. Programa Agrinho, 2020. Disponível em: https://www.agrinho.com.br/institucional/programa. Acesso em: 10 mai. 2020.

BERTOLINI, A. R.; CAÚLA, B. Q. Educação ambiental: o hiato entre a teoria e a realidade. In: CAÚLA, B. Q. et al. Diálogo ambiental, constitucional e internacional. Fortaleza: Premius, 2013.

BRASIL. Lei n. 6.938. Diário Oficial da União, 31 de agosto de 1981, Brasília, 1981.

. Constituição da República Federativa do Brasil de 1988. Diário Oficial da União, 5 de outubro de 1988, Brasília, 1988.

. Lei n. 9.795. Diário Oficial da União, 27 de abril de 1999, Brasília, 1999.

COMISSÃO MUNDIAL SOBRE MEIO AMBIENTE E DESENVOLVIMENTO. Nosso Futuro Comum. Rio de Janeiro: Fundação Getúlio Vargas, 1991.

DIAS, G. F. Educação ambiental: princípios e práticas. São Paulo: Gaia, 2017.

GOHN, M. da G. Conselhos gestores e participação sociopolítica. São Paulo: Cortez, 2011.

GONÇALVES, A.; COSTA, J. A. F. Governança ambiental global: possibilidades e limites. In: GRANZIERA, Maria Luiza Machado; REI, Fernando (Coords.). Direito Ambiental Internacional: avanços e retrocessos. São Paulo: Atlas, 2015.

JACOBI, P. Educação ambiental, cidadania e sustentabilidade. Cadernos de Pesquisa, n. 118, p. 189-205, mar. 2003.

LAGO, A. A. C. do. Estocolmo, Rio, Joanesburgo: o Brasil e as três conferências ambientais das Nações Unidas. Brasília: Fundação Alexandre de Gusmão, Instituto Rio Branco, 2006.

LEFF, E. Saber ambiental: sustentabilidade, racionalidade, complexidade, poder. Petrópolis: Vozes, 2001.

LEITE, J. R. M.; CAETANO, Matheus Almeida. As facetas do significado de desenvolvimento sustentável - uma análise através do Estado de Direito Ambiental. Revista Internacional de Direito e Cidadania, São Paulo, n. 13, p. 131-148, 2012.

LOUREIRO, C. F. B. Educação ambiental transformadora, 2004. Disponível em: http://files.zeartur.webnode.com.br/200000044-e06b4e1651/Identidades_EA_Brasileira.pdf\#page=67. Acesso em: 05 fev. 2020.

LUCON, O. Desenvolvimento sustentável. In: REI, Fernando et al. Direito e desenvolvimento: uma abordagem sustentável. São Paulo: Saraiva, 2013.

MATOS, M. C. de F. G. Panorama da educação ambiental brasileira a partir do V Fórum Brasileiro de Educação Ambiental. Rio de Janeiro, 2009. 138 f. Dissertação (Mestrado em Educação), Universidade 
Federal do Rio de Janeiro.

MAZZUOLI, V. de O.; TEIXEIRA, G. de F. M. O Direito Internacional do Meio Ambiente e o greening da Convenção Americana sobre Direitos Humanos. Revista Direito GV, São Paulo, v. 9, n. 1, p. 199-242, 2013.

McCORMICK, J. Rumo ao paraíso: a história do movimento ambientalista. Tradução de Marco Antônio Esteves da Rocha e Renato Aguiar. Rio de Janeiro: Relume-Dumará, 1992.

MILARÉ, É. Direito do ambiente. São Paulo: Revista dos Tribunais, 2018.

MINISTÉRIO DA EDUCAÇÃO. Resolução CNE/CES n. 9. Diário Oficial da União, 29 de dezembro de 2004, Brasília, 2004.

. Resolução CNE/CES n. 5. Diário Oficial da União, 17 de dezembro de 2018, Brasília, 2018.

Cadastro Nacional de Cursos e Instituições de Educação Superior Cadastro e-MEC, 2020.

Disponível em: http://emec.mec.gov.br/. Acesso em: 05 fev. 2020.

OLIVEIRA, L. P. S.; MONT’ALVERNE, T. C. F. A evolução da noção de desenvolvimento sustentável nas conferências das Nações Unidas. In: GRANZIERA, M. L. M.; REI, F. (Coord.). Direito Ambiental Internacional: avanços e retrocessos. São Paulo: Atlas, 2015.

ORGANIZAÇÃO DAS NAÇÕES UNIDAS. Declaration of the United Nations Conference on the

Human Environment. Nova Iorque, 1972. Disponível em: http://www.un-documents.net/unchedec.htm. Acesso em: 05 maio 2019.

PUHL, M. J. Os princípios republicanos e a educação ambiental. Tese (Doutorado em Educação nas Ciências) - Universidade Regional do Noroeste do Estado do Rio Grande do Sul, Ijuí, 2016.

QUINTAS, J. S. Educação no processo de gestão ambiental pública: a construção do ato pedagógico. In: LAYRARGUES, P. P.; BERNARDO, C. F.; SOUZA, R. (Org.) Repensar a educação ambiental: um olhar crítico. São Paulo: Cortez, 2009.

RIBEIRO, W. C. A ordem ambiental internacional. São Paulo: Contexto, 2005.

SARLET, I. W.; FENSTERSEIFER, T. Direito ambiental: introdução, fundamentos e teoria geral. São Paulo: Saraiva, 2014.

SARLET, I. W.; FENSTERSEIFER, T. O direito constitucional-ambiental brasileiro e a governança judicial ecológica: estudo à luz da jurisprudência do Superior Tribunal de justiça e do Supremo Tribunal Federal.

Revista da Academia Brasileira de Direito Constitucional (Constituição, Economia e Desenvolvimento), Curitiba, 2019, v. 11, n. 20, p. 42-110, jan./jul. 2019.

SEN, A. Desenvolvimento como liberdade. Tradução de Laura Teixeira Motta. São Paulo: Companhia das 
Letras, 2010.

SOUZA FILHO, C. F. M. de. De como a natureza foi expulsa da modernidade. Revista Crítica de Direito, São Paulo, v. 66, n. 5, p. 88-104, ago./dez. 2015.

ORGANIZAÇÃO DAS NAÇÕES UNIDAS PARA A EDUCAÇÃO, A CIÊNCIA E A CULTURA - UNESCO. Década das Nações Unidas da Educação para o Desenvolvimento Sustentável: 2005-2014. Brasília: 2005.

ORGANIZAÇÃO DAS NAÇÕES UNIDAS PARA A EDUCAÇÃO, A CIÊNCIA E A CULTURA - UNESCO. Shaping the future we want: UN Decade of Education for Sustainable Development (2005-2014). Disponível em: https://unesdoc.unesco.org/ark:/48223/pf0000230302. Acesso em: 05 maio 2019.

VEIGA, J. E. da. A desgovernança mundial da sustentabilidade. São Paulo: 34, 2013. , J. E. da. Para entender o desenvolvimento sustentável. São Paulo: 34, 2015. 